Article

\title{
Differential Expression of Decorin in Metastasising Colorectal Carcinoma Is Regulated by $m i R-200 c$ and Long Non-Coding RNAs
}

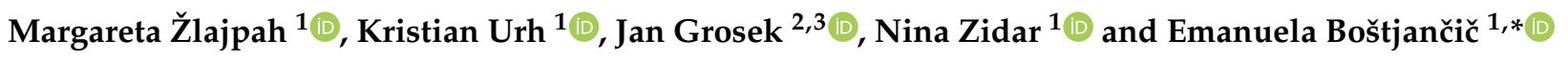 \\ 1 Institute of Pathology, Faculty of Medicine, University of Ljubljana, 1000 Ljubljana, Slovenia; \\ margareta.zlajpah@mf.uni-lj.si (M.Ž.); kristian.urh@mf.uni-lj.si (K.U.); nina.zidar@mf.uni-lj.si (N.Z.) \\ 2 Department of Abdominal Surgery, University Medical Centre Ljubljana, 1000 Ljubljana, Slovenia; \\ jan.grosek@kclj.si \\ 3 Faculty of Medicine, University of Ljubljana, 1000 Ljubljana, Slovenia \\ * Correspondence: emanuela.bostjancic@mf.uni-lj.si
}

check for updates

Citation: Žlajpah, M.; Urh, K.; Grosek, J.; Zidar, N.; Boštjančič, E. Differential Expression of Decorin in Metastasising Colorectal Carcinoma Is Regulated by miR-200c and Long Non-Coding RNAs. Biomedicines 2022, 10, 142. https://doi.org/ 10.3390/biomedicines 10010142

Academic Editors: Antonio Biondi and Marco Vacante

Received: 17 November 2021

Accepted: 6 January 2022

Published: 10 January 2022

Publisher's Note: MDPI stays neutral with regard to jurisdictional claims in published maps and institutional affiliations.

Copyright: (c) 2022 by the authors Licensee MDPI, Basel, Switzerland. This article is an open access article distributed under the terms and conditions of the Creative Commons Attribution (CC BY) license (https:// creativecommons.org/licenses/by/ $4.0 /)$.

\begin{abstract}
Decorin $(\mathrm{DCN})$ is one of the matricellular proteins that participate in normal cells' function as well as in cancerogenesis. While its expression in primary tumours is well known, there is limited data about its expression in metastases. Furthermore, the post-transcriptional regulation of $D C N$ is still questionable, although it is well accepted that it is an important mechanism of developing metastatic cancer. The aim of our study was to analyse the expression of DCN and its potential regulatory ncRNAs in metastatic colorectal carcinoma (CRC). Nineteen patients with metastatic CRC were included. Using qPCR, we analysed the expression of DCN, miR-200c and five lncRNAs (LUCAT1, MALAT1, IncTCF7, XIST, and ZFAS1) in lymph node and liver metastases in comparison to the invasive front and central part of a primary tumour. Our results showed insignificant upregulation of DCN and significant upregulation for miR-200c, MALAT1, IncTCF7 and ZFAS1 in metastases compared to the primary tumour. miR-200c showed a positive correlation with $D C N$, and the aforementioned lncRNAs exhibited a significant positive correlation with miR200c expression in metastatic CRC. Our results suggest that DCN as well as miR-200c, MALAT1, IncTCF7 and ZFAS1 contribute to the development of metastases in CRC and that regulation of DCN expression in CRC by ncRNAs is accomplished in an indirect manner.
\end{abstract}

Keywords: colorectal carcinoma; liver metastasis; lymph node metastasis; decorin; miR-200c; lncRNA

\section{Introduction}

Decorin (DCN) is one of the matricellular proteins belonging to the small leucine-rich proteoglycan family. DCN is transcribed and translated by fibroblasts, stressed vascular endothelial cells and smooth muscle cells [1]. It was first discovered as a protein-decorating collagen fibre [2], but today it is known as an important regulator of collagen fibrillogenesis $[3,4]$. Moreover, DCN participates in other cellular functions such as migration, proliferation, apoptosis and differentiation [5]. DCN also binds to growth factors, such as TGF $\beta$, but on the other side, it inhibits receptor tyrosine kinases, e.g., EGFR, IGF-IR and met $[1,6]$. Consequently, the latter bioactivities have been attributed to evoke potent tumour repression [1].

$\mathrm{DCN}$ is one of many proteins in the extracellular matrix that provides not only physical scaffolds but also regulates many cellular processes, including cancerogenesis [7]. Several studies reported that a lack of DCN leads to spontaneous tumour development [2]. It has been shown that the expression of DCN is reduced in many carcinomas, e.g., in the ovaries, lung, oesophagus and others $[2,4,8,9]$, where DCN is mainly synthesised by stromal cells, whereas it is almost completely absent in tumorous cells [9] or rarely by actively dividing normal cells [3]. The expression of DCN was also shown in some studies to be 
reduced in colorectal carcinoma (CRC) [3,4]; however, we [10] and others [9] reported a higher expression of DCN in CRC. We also showed that the DCN gene is upregulated regardless of the presence of lymph node metastasis, and it was the only gene significantly associated with the presence of lymph node metastasis in CRC. In the same study, we also observed an altered expression of DCN at the invasive front of CRC compared to its central part [10]. The extracellular matrix, including DCN, is used by disseminating tumorous cells to insulate themselves from the insult of haemodynamic fluid shear stress in circulation and to contribute to the establishment of a premetastatic niche by reorganizing the pre-existing extracellular matrix structure [11].

Post-transcriptional regulation of DCN is still questionable, although it is well accepted that its aberrant expression is important in developing lymph node and liver metastases in cancer, including CRC [12]. There are numerous known mechanisms of post-transcriptional regulation of mRNAs, the most frequently analysed being non-coding RNA (ncRNA) [13-16]. Among known groups of ncRNAs, miRNAs (microRNAs) and lncRNAs (long non-coding RNAs) have proven regulatory function and contribution to the development of metastasis in different carcinomas $[17,18]$. Up until now, no miRNA was confirmed to regulate $D C N$, and one miRNA, i.e., miR-200c, was predicted using bioinformatics analysis [19]. However, in vitro or in vivo correlation between expression of miR-200c and DCN has not been shown yet.

None of the lncRNAs have yet been proven to directly regulate $D C N$. In contrast, there are numerous proven lncRNAs that are validated to sponge $m i R-200 c$ in different cancers, the predicted regulatory miRNA of DCN [20-28]. However, their exact role in regulating $m i R-200 c$ in $C R C$ has yet to be elucidated. Furthermore, while there are numerous studies describing the expression of DCN in CRC [3-5,9,12], there is limited data about the expression of mRNA DCN in lymph node and liver metastases. So far, only one study [29] reported a lower expression of the protein DCN in liver metastases of CRC.

Therefore, the aim of our study was to analyse the expression of DCN in the central part and the invasive front in comparison to the lymph node and liver metastases to further explore its role in advanced CRC. Furthermore, we tried to indirectly confirm previously predicted regulation of $D C N$ on mRNA level by miR-200c [19] and to analyse whether experimentally validated lncRNAs might act as sponges for miR-200c.

\section{Materials and Methods}

Tissue samples from patients with CRC with lymph node and/or liver metastases were included in the study. For routine histopathologic examination, all tissue samples were fixed for $24 \mathrm{~h}$ in 10\% buffered formalin and embedded in paraffin (FFPE). After fixation and embedding, tissues were cut into $4 \mu \mathrm{m}$ slides and stained with haematoxylin and eosin for routine histopathological examination and classification according to pTNM (pathologic Tumour Node Metastasis). Samples were collected retrospectively from the archives of the Institute of Pathology, Faculty of Medicine, University of Ljubljana. On the basis of clinical and histopathological features, samples were divided into three groups: patients with CRC with lymph node metastases, patients with liver metastases but without lymph node metastases and patients with carcinoma with lymph node and liver metastases.

The investigation was carried out following the rules of the Declaration of Helsinki. The study was approved by the National Medical Ethics Committee (Republic of Slovenia, Ministry of Health).

\subsection{Isolation of Total RNA from Tissue Cores}

Tissue cores from the nodal and liver metastasis of CRC were punched from FFPE tissue blocks using a $600 \mu \mathrm{m}$ needle. MagMax FFPE DNA/RNA Ultra kit (Applied Biosystems, Thermo Fisher Scientific, Inc.; Waltham, MA, USA) was used to extract the total RNA from three punches for each isolation. The total RNA extraction was isolated following the manufacturer's instructions, with one modification: protease digestion was performed overnight with mixing for $15 \mathrm{~s}$ at $300 \mathrm{rpm}$ every $4 \mathrm{~min}$ instead of $1 \mathrm{~h}$. Apart 
from the deparaffinization solution (Xylene; Sigma-Aldrich; St. Louis, MO, USA) and the ethanol (Merck KGaA; Darmstadt, Germany), all the reagents were from Applied Biosystems (Thermo Fisher Scientific, Inc.). The quantity of RNA was measured with NanoDrop ND-1000 (Thermo Fisher Scientific, Inc.) by measuring the absorbance at $260 \mathrm{~nm}$.

\subsection{Selection of $\ln c R N A s$}

After searching through the publication, we have identified 9 lncRNAs that were suggested to sponge $m i R-200 c$ in different types of cancer or in other diseases [20-27,30]. Among the identified lncRNAs, we have chosen those that could successfully detect specific products of less than $100 \mathrm{bp}$ using TaqMan probe. For the purpose of expression analysis, we, therefore, selected the following lncRNAs: LUCAT1, MALAT1, IncTCF7, XIST and ZFAS1 [20-22,27,28]. The other four lncRNAs, namely ATB, LINC02582, N-BLR and ZEB1AS1 [23-26], were excluded from further analysis due to the longer amplification product of pre-designed TaqMan probes.

\subsection{Reverse Transcription and Quantitative PCR ( $q P C R$ )}

Associated lncRNAs LUCAT1, MALAT1, lncTCF7, XIST, ZFAS1 and mRNAs for DCN (Table 1) were analysed relative to the geometric mean of RGs, IPO8 and B2M. lncRNAs and mRNAs were reverse transcribed using an OneTaq RT-PCR Kit (New England Biolabs, Ipswich, MA, USA) using random primers according to the manufacturer's instructions. Reverse transcription (RT) reactions were started with $3.0 \mu \mathrm{L}(60 \mathrm{ng})$ of total RNA and $1.0 \mu \mathrm{L}$ of Random Primer Mix incubated at $70{ }^{\circ} \mathrm{C}$ for $5 \mathrm{~min}$. The $10 \mu \mathrm{L}$ RT master mix included $5.0 \mu \mathrm{L}$ of M-MuLV Reaction Mix, $1.0 \mu \mathrm{L}$ of M-MuLV reverse transcriptase and $4.0 \mu \mathrm{L}$ of reaction mix after random priming. The reaction conditions were $25^{\circ} \mathrm{C}$ for $5 \mathrm{~min}$, $42{ }^{\circ} \mathrm{C}$ for $60 \mathrm{~min}$ and $80{ }^{\circ} \mathrm{C}$ for $4 \mathrm{~min}$.

Table 1. List of used TaqMan gene expression assay.

\begin{tabular}{cc}
\hline Gene or lncRNA & Assay ID \\
\hline B2M & Hs99999907_m1 \\
IPO8 & Hs00183533_m1 \\
DCN & Hs00266491_m1 \\
LUCAT1 & Hs04978593_m1 \\
MALAT1 & Hs0191077_s1 \\
lncTCF7 & Hs01556515_m1 \\
ZFAS1 & Hs01379985_m1 \\
XIST & Hs01077162_m1 \\
RNU6B & ID 001093 \\
miR-1274b & ID 002884 \\
miR-200c & ID 002300 \\
\hline
\end{tabular}

After cDNA synthesis, a preamplification reaction was performed using the TaqMan PreAmp mastermix (Applied Biosystems; Thermo Fisher Scientific, Inc.) following the manufacturer's protocol. The TaqMan Gene Expression Assays, listed in Table 1, were pooled, followed by dilution to $0.2 \times$ using Tris-EDTA buffer solution, pH 8.0 (SigmaAldrich; Merck KGaA). The thermocycling conditions were as follows: $10 \mathrm{~min}$ at $95{ }^{\circ} \mathrm{C}$ and 10 cycles of $15 \mathrm{sec}$ at $95^{\circ} \mathrm{C}$ and $4 \mathrm{~min}$ at $60^{\circ} \mathrm{C}$.

For miRNAs, reverse transcription looped primers for specific RT of miRNAs and a MicroRNA TaqMan RT kit (Applied Biosystems, Foster City, CA, USA) were utilised following the manufacturer's protocol. RNU6B and miR-1247b were used as reference genes (RGs). miR-200c was tested relative to the geometric mean of expression of RNU6B and $m i R-1247 b$ (Table 1 ). Briefly, a $10 \mu \mathrm{L}$ RT reaction master mix was performed with $10 \mathrm{ng}$ of total RNA sample, $1.0 \mu \mathrm{L}$ of MultiScribe Reverse Transcriptase (50 U/ $\mu \mathrm{L}), 1.0 \mu \mathrm{L}$ of Reverse Transcription Buffer $(10 \times), 0.1 \mu \mathrm{L}$ of dNTP $(100 \mathrm{mM}), 0.19 \mu \mathrm{L}$ RNAase inhibitor $(20 \mathrm{U} / \mu \mathrm{L})$, and $2.0 \mu \mathrm{L}$ of RT primer $(5 \times)$. The reaction conditions were $16^{\circ} \mathrm{C}$ for $30 \mathrm{~min}$, $42{ }^{\circ} \mathrm{C}$ for $30 \mathrm{~min}, 85^{\circ} \mathrm{C}$ for $5 \mathrm{~min}$. 
qPCR reactions were performed using TaqMan technology with FastStart Essential DNA Probe Master (Roche Diagnostics, Basel, Switzerland). Each qPCR reaction contained appropriately diluted cDNA, $2 \times$ FastStart Essential DNA Probe Master (Roche Diagnostics) and 20× TaqMan gene expression assay, listed in Table 1. All qPCR reactions were conducted on a Rotor-Gene $Q$ system (Qiagen $\mathrm{GmbH}$ ), and each sample was run twice. The thermocycling conditions for gene expression were $10 \mathrm{~min}$ at $95^{\circ} \mathrm{C}$ and 40 cycles of $15 \mathrm{~s}$ at $95^{\circ} \mathrm{C}$ and $1 \mathrm{~min}$ at $60^{\circ} \mathrm{C}$. For miRNAs, the thermocycling conditions were $95^{\circ} \mathrm{C}$ for $10 \mathrm{~min}, 40$ cycles for $15 \mathrm{~s}$ at $95^{\circ} \mathrm{C}$ and for $60 \mathrm{~s}$ at $60{ }^{\circ} \mathrm{C}$. The signal was collected at the endpoint of every cycle.

To calculate the efficiency of qPCR reactions, pools of RNA samples of each group were created. The RNA pools were reverse transcribed, and in the cases of lncRNAs and mRNAs, the pools were preamplified as described above and diluted in 4 steps, ranging from 5- to 625-fold dilution; qPCR reactions were run in triplicate as described above.

\subsection{Statistical Analysis}

To calculate relative gene expression, $\mathrm{Cq}$ values were corrected according to Latham et al. [31]. To obtain $\Delta \mathrm{Cq}$, the $\mathrm{Cq}$ of the gene/lncRNA/miRNA of interest was deducted from the geometric mean of $\mathrm{Cq}$ values of the reference genes. In $\mathrm{CRC}$, the $\mathrm{mR}$ NAs', miRNAs' and lncRNAs' expression differences were compared between both the central part and invasive front of $C R C$, the central part of CRC and lymph node metastasis and the central part of CRC and liver metastasis using $\triangle \mathrm{Cq}$ and the Wilcoxon rank test. For all correlations/associations, Spearman rank-order correlation was used. All statistical analyses were performed using SPSS analytical software v24 (IBM Corp., Armonk, NY, USA), with a cut-off of $p \leq 0.05$.

\section{Results}

\subsection{Patients and Tissue Samples}

In total, we analysed 63 tissue samples from 19 patients with CRC with lymph node and/or liver metastases. There were 13 males and 6 women, with a mean age of $70 \pm 14$. The invasive front and the central part of CRC were available in all cases, whereas lymph node metastases were available in 15 and liver metastases in 10 cases. Detailed information is provided in Table 2 .

Table 2. Patients' characteristics and pTNM status.

\begin{tabular}{|c|c|c|c|c|}
\hline Group & $\begin{array}{c}\text { Age } \\
(\text { Mean } \pm \text { SD) }\end{array}$ & Male:Female & pTNM & Tissue Samples \\
\hline $\mathrm{N}+\mathrm{M} 0$ & $74.2 \pm 13.4$ & $7: 2$ & $\begin{array}{c}\text { pT3N1 }(n=6) \text { pT4N2M0 }(n=1) \\
\text { pT4N2M1 }(n=2)\end{array}$ & $\begin{array}{c}\text { Invasive front }(n=9) \\
\text { Central part }(n=9) \\
\text { Lymph node metastasis }(n=9)\end{array}$ \\
\hline N0 M+ & $70.5 \pm 4.9$ & $2: 2$ & $\begin{array}{c}\text { pT1 }(n=1) \\
\text { pT3N0 }(n=1) \text { pT3N0M1 }(n=1) \\
\text { pT4aN1a }(n=1)\end{array}$ & $\begin{array}{c}\text { Invasive front }(n=4) \\
\text { Central part }(n=4) \\
\text { Liver metastasis }(n=4)\end{array}$ \\
\hline $\mathrm{N}+\mathrm{M}+$ & $63.8 \pm 15.5$ & $4: 2$ & $\begin{array}{c}\text { pT3N1 }(n=1) \text { pT3N2M1 }(n=1) \\
\text { pT4N1M1 }(n=4)\end{array}$ & $\begin{array}{c}\text { Invasive front }(n=6) \\
\text { Central part }(n=6) \\
\text { Lymph node metastasis }(n=6) \\
\text { Liver metastasis }(n=6)\end{array}$ \\
\hline
\end{tabular}

3.2. Expression of Decorin in the Central Part and the Invasive Front of Primary Colorectal Carcinoma in Comparison to Lymph Node and Liver Metastases

The expression of $D C N$ was present in all analysed groups; the results are presented in Figure 1. Gene expression of $D C N$ was downregulated in the central part when compared to the invasive front of primary CRC, in lymph nodes or in liver metastases. The downregulation was observed in the central part and the invasive front of CRC compared to lymph node and liver metastasis. None of the comparisons yielded statistically significant results. 


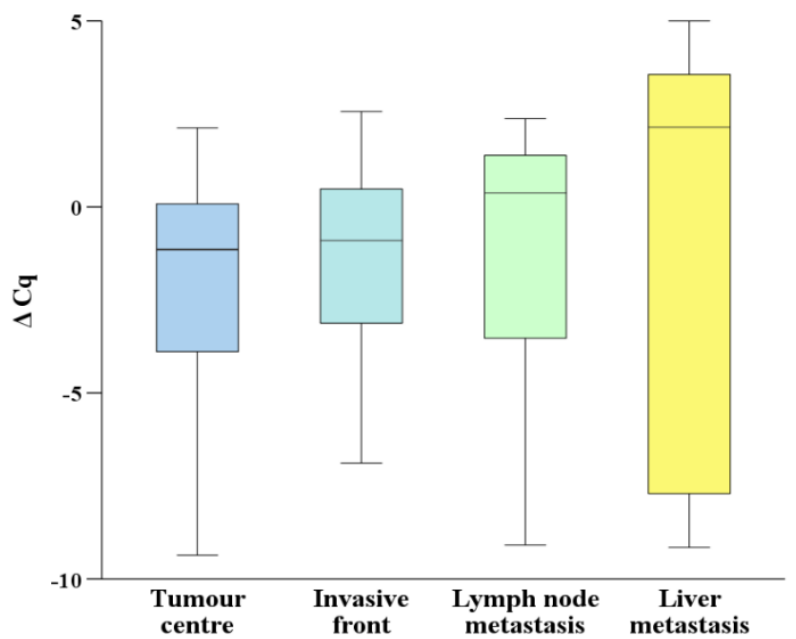

Figure 1. Expression of decorin in the central part and the invasive front of primary colorectal carcinoma in lymph node and liver metastases. Legend: $\Delta \mathrm{Cq}$, delta Cq.

3.3. Expression of miR-200c in the Central Part and Invasive Front of Primary Colorectal Carcinoma in Comparison to Lymph Node and Liver Metastases

The expression of $m i R-200 c$ was present in all analysed groups and is presented in Figure 2. The expression of $m i R-200 c$ was upregulated, but not significant, in the central part of CRC in comparison to the invasive front. The expression of $m i R-200 c$ was significantly downregulated in the central part of CRC as well as the invasive front when compared either to lymph node or liver metastases $(p=0.001$ and $p=0.008$ in the central part and $p=0.001$ and $p=0.008$ at the invasive front).

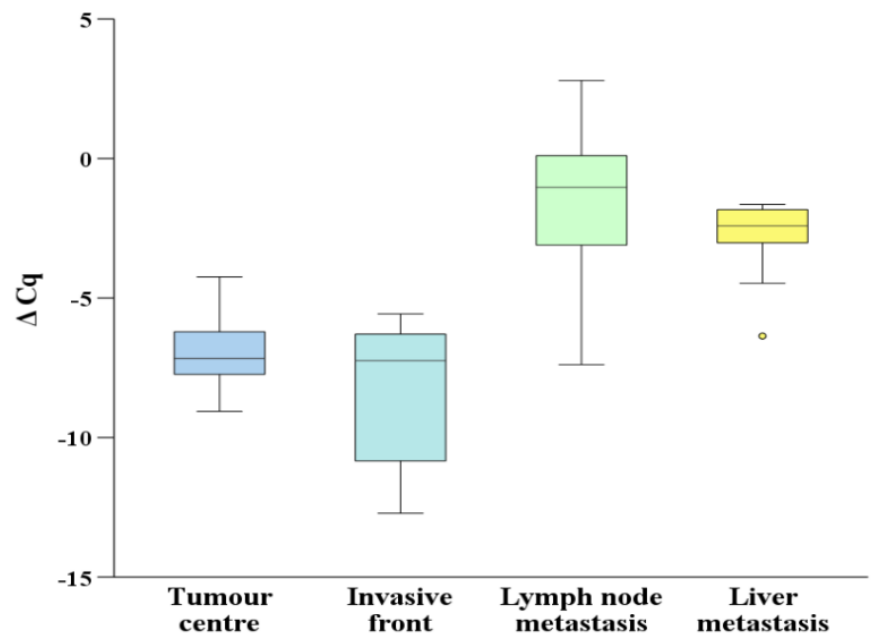

Figure 2. Expression of $m i R-200 c$ in the central part and the invasive front of primary colorectal carcinoma in lymph node and liver metastases. Legend: $\Delta \mathrm{Cq}$, delta $\mathrm{Cq} ;{ }^{\circ}$, high potential outlier as defined by SPSS.

\subsection{Expression of IncRNAs in the Central Part and the Invasive Front of Primary Colorectal} Carcinoma in Comparison to Lymph Node and Liver Metastases

When comparing the central part of CRC to the invasive front, LUCAT1, XIST and ZFAS1 were non-significantly upregulated in all groups, while MALAT1 and IncTCF7 were non-significantly downregulated.

When comparing lymph node metastases to both the central part and invasive front of CRC, the difference in expression of MALAT1 was significant in both cases $(p=0.041$ and $p=0.013$, respectively) and of $\operatorname{lncTCF7}$ only when compared to the invasive front $(p=0.050)$. The expression of LUCAT1 was upregulated in the central part of CRC when 
compared to the expression in lymph node metastasis. LUCAT1, XIST and ZFAS1 did not show any statistically significant change in expression when comparing the central part of CRC or the invasive front to the lymph node metastasis.

Additionally, all investigated lncRNAs were downregulated in the central part and the invasive front of CRC when compared to liver metastasis. The difference in expression of the investigated lncRNAs in the invasive front of CRC was not significant when compared to the expression in liver metastases. Nonetheless, significant differences were observed in the expression of MALAT1, IncTCF7 and ZFAS1 in the central part of CRC when compared to the expression in liver metastasis $(p=0.011, p=0.013$ and $p=0.007$, respectively). The expression of the selected lncRNAs is presented in Figure 3.
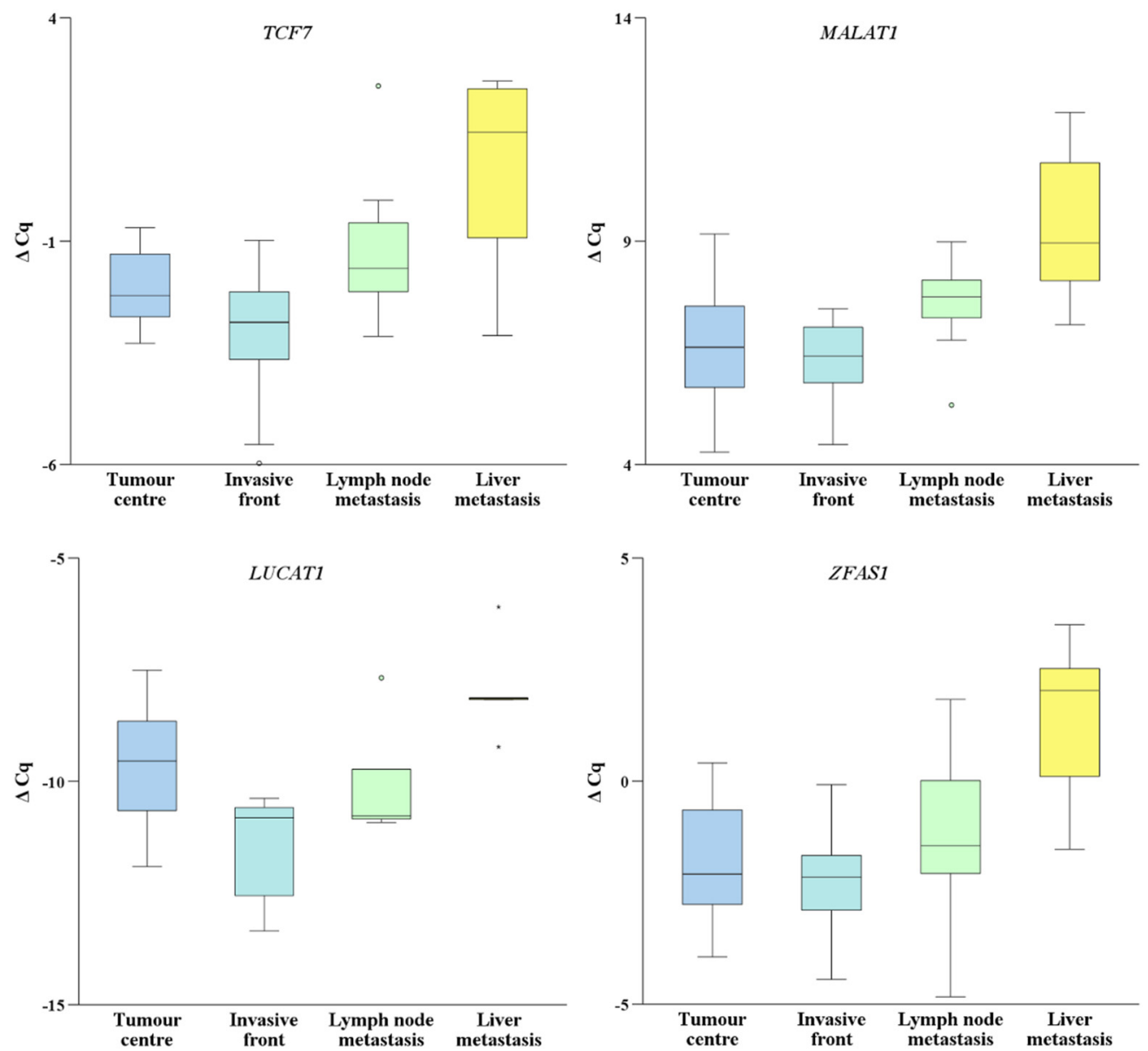

Figure 3. Expression of lncRNAs in the central part and the invasive front of primary colorectal carcinoma in lymph node and liver metastases. Legend: $\Delta \mathrm{Cq}$, delta $\mathrm{Cq} ;{ }^{\circ}$, high potential outlier as



\subsection{Correlations between miR-200c, Target Gene Decorin and the Investigated IncRNAs}

XIST did not correlate significantly with any of the other investigated lncRNAs, miR-200c or DCN. miR-200c had several statistically significant correlations: a weak positive correlation with DCN, IncTCF7 and ZFAS1 and a moderate positive correlation with $M A L A T 1$. Additionally, DCN correlated significantly and positively with several of the investigated lncRNAs; a weak positive correlation was observed with lncTCF7 and ZFAS1, while a moderate positive correlation was observed with MALAT1. Furthermore, several of the investigated lncRNAs correlated significantly and positively with each other, the strongest being between MALAT1 and ZFAS1. Other comparisons and complete data on correlation coefficients and corresponding $p$-values are summarised in Table 3. 
Table 3. Significant Spearman correlation coefficients and corresponding $p$-values for investigated comparisons between the miR-200c, decorin and analysed lncRNAs.

\begin{tabular}{cccccccc}
\hline $\begin{array}{c}\text { Correlations and } \\
\boldsymbol{p} \text {-Values }\end{array}$ & DCN & miR-200c & LUCAT1 & MALAT1 & XIST & lncTCF7 & ZFAS1 \\
\hline DCN & 1 & $0.296(0.027)$ & $/$ & $0.452(<0.001)$ & $/$ & $0.278(0.034)$ & $0.357(0.006)$ \\
miR-200c & $0.296(0.027)$ & 1 & $/$ & $0.425(0.001)$ & $/$ & $0.313(0.018)$ & $0.375(0.004)$ \\
LUCAT1 & $/$ & $/$ & 1 & $0.633(<0.001)$ & $/$ & $0.613(0.001)$ & $0.516(0.006)$ \\
MALAT1 & $0.452(<0.001)$ & $0.425(0.001)$ & $0.633(<0.001)$ & 1 & $/$ & $0.741(<0.001)$ & $0.746(<0.001)$ \\
XIST & $/$ & $/$ & $/$ & $/$ & 1 & $/$ \\
InCTCF7 & $0.278(0.034)$ & $0.313(0.018)$ & $0.613(0.001)$ & $0.741(<0.001)$ & $/$ & 1 & $0.641(<0.001)$ \\
ZFAS1 & $0.357(0.006)$ & $0.375(0.004)$ & $0.516(0.006)$ & $0.746(<0.001)$ & $/$ & $0.641(<0.001)$ \\
\hline
\end{tabular}

\section{Discussion}

The purpose of this study was to evaluate the expression of $D C N$ in the central part and the invasive front of primary CRC in comparison to lymph node and liver metastases. Our results showed that the expression of $D C N$ was downregulated in the central part and the invasive front of CRC compared to lymph node and liver metastases. Further, we examined whether the expression of $m i R-200 c$ was negatively correlated to the expression of $D C N$ and validated the expression of some lncRNAs as potential sponges for miR-200c. The Spearman correlation coefficient showed a positive, statistically significant correlation between the expression of DCN and miR-200c as well as between lncRNAs MALAT1, IncTCF7 and ZFAS1 and miR-200c. These three lncRNAs were also the only ones that were significantly downregulated in the central part or the invasive front of CRC when compared to metastases.

Previous studies of $D C N$ expression in CRC were mostly based on a comparison between the expression in tumorous and healthy mucosa [3,4,32]. Our study, however, compared the expression between the central part and the invasive front of CRC to lymph node and liver metastases. The expression of $D C N$ was slightly downregulated in both the central part and invasive front of CRC in comparison to lymph node and liver metastases, but the difference in expression was not significant. There are limited data about the heterogeneity of expression of either protein or the mRNA of DCN in different parts of CRC. In our previous study, we compared the expression of $D C N$ in the central part to the expression of $D C N$ in the invasive front, and this was further confirmed in the present study [10]. Another group analysed the expression pattern of protein DCN in healthy mucosa, primary tumour and liver metastases of CRC [29]. Immunohistochemistry conducted by Reszegi et al. showed that the expression of DCN was downregulated in the stroma of the primary tumour compared to the stroma of healthy mucosa. In the liver metastases, the expression of the protein was the same when compared to the adjacent liver tissue but significantly lower than in the normal colon and primary CRC [29]. Based on these and our observations, we speculated that the decreased expression of protein DCN and slight upregulation of mRNA DCN in liver metastases compared to the primary tumour may reflect the regulation at the post-transcription level by ncRNAs.

Regarding the gradient of expression of $m i R-200 c$ in CRC, we did not observe any changes in expression; however, some studies reported upregulation of miR-200c in the central part in comparison to the invasive front of CRC [33,34]. In concordance with our results of $m i R-200 c$ expression, Hur et al. [35] also found downregulation of miR-200c in primary CRC in comparison to liver metastases. In contrast, another study showed miR-200c upregulation in primary CRC compared to liver metastases [36]. However, to the best of our knowledge, this was the first report of miR-200c expression in lymph node metastases of CRC in comparison to primary CRC besides our previous study that focused on the epithelial-mesenchymal transition [37]. Furthermore, our results suggest that in contrast to a previous bioinformatics analysis [19], miR-200c has a positive influence on $D C N$ expression in CRC metastases. We can only speculate that the observed positive correlation between the expression of miR-200c and DCN suggests that $D C N$ is regulated by 
$m i R-200 c$ in an indirect manner (through another factor or binding of $m i R-200 c$ on promotor region of $D C N$ ) rather than a direct manner (binding of $m i R-200 c$ to the $3^{\prime}$-UTR of $D C N$ ).

Similarly, the expression of the three of five investigated lncRNAs positively correlated to the expression of $m i R-200 c$; therefore, sponging of miR-200c by selected miRNAs is probably not the case. Speculatively, all these ncRNAs might be, for instance, under the regulation by the same transcription factor. However, all of the five investigated lncRNAs had already been reported to be upregulated in CRC in comparison to healthy mucosa. Moreover, the expression of all lncRNAs had been positively correlated to the development of metastases [38-47]. According to the available publications, there is no data regarding a comparison of the expression of investigated lncRNAs in the central part of CRC to that in the invasive front, lymph node and liver metastases of CRC.

Although LUCAT1 was downregulated in our samples of primary CRC in comparison to liver metastasis, downregulation did not reach statistical significance. The lncRNAs' expression profiles of CRC tissue from patients with liver metastases to those without metastases revealed that LUCAT1 is a liver metastasis-associated lncRNA. It was also shown that knockdown of LUCAT1 could significantly inhibit cells' invasion, suggesting that it might play an important role in liver metastasis by promoting cells' invasion [38]. Another study confirmed that LUCAT1 promoted metastases through the stimulating migration and invasion of CRC cell lines [39].

We observed a significantly downregulated expression of MALAT1 in the central part of CRC in comparison to lymph node and liver metastases. Similar results were reported by Liu et al., who found the expression of MALAT1 to correlate to liver metastasis status and to be significantly downregulated in CRC tissue compared to excised liver metastases. They also showed that MALAT1 was significantly upregulated in primary CRC patients who developed liver metastasis within 5 years of initial diagnosis, compared to the primary CRC of patients with no metastasis. A positive signature comprising of high MALAT1 also correlated with the progression to high-grade CRC [40]. Our study further supports the observation of a significantly lower expression of lncRNAs in primary CRC in comparison to metastases.

LncRNA IncTCF7 was found to be downregulated in the central part and the invasive front of CRC when compared to lymph node and liver metastases, respectively. IncTCF7 is believed to have an essential role in maintaining cancer stem cell self-renewal. Its expression has been shown to correlate with lymph node metastasis and stage, promote invasion and migration of tumour cells [41]. Another study supported this observation and additionally showed its significant association with depth of invasion. IncTCF7 also promoted proliferation. As such, it might predict progression, facilitate tumour growth and promote the formation of metastases in CRC [42].

However, in our study, we were not able to confirm any statistically significant change in expression for XIST, but we observed an insignificant upregulation in primary CRC in comparison to lymph node metastases and no change in the expression in primary CRC in comparison to liver metastases. However, it has been reported that XIST expedited and promoted the growth of metastases in CRC [43,44].

Finally, we observed a downregulation of lncRNA ZFAS1 in primary CRC compared to lymph node and liver metastases. The expression of ZFAS1 was shown to be lower in primary CRC than in metastasis, and it was shown to be positively correlated with lymph node invasion and pTNM stage [45]. ZFAS1 was also associated with an aggressive CRC phenotype. Its knockdown inhibited cell proliferation and invasion in vitro and metastases in vivo [46]. Furthermore, a high expression of ZFAS1 was observed in advanced stages of CRC; its silencing reduced the cells' migration and invasion abilities, supporting the function of ZFAS1 in the development of metastases of CRC [47].

There are two main limitations of our study. The first is the small number of patients with an unequal female-to-male ratio. However, this was the consequence of collecting the samples from the same patients with CRC from primary tumour, lymph node and/or liver metastases. The second one is the lack of functional validation of regulation of $D C N$ by 
miR-200c. However, our results suggest that this could be a rather complex investigation since we observed the positive rather than expected negative correlation between miR-200c and $D C N$.

\section{Conclusions}

In conclusion, there are three main findings from our study. First, we found an insignificant downregulation of the $D C N$ gene in primary CRC in comparison to metastases, which, regarding the reported upregulated protein expression in primary CRC in comparison to metastases, suggests that there is a post-transcriptional level of the regulation of $D C N$. Second, we observed a significant downregulation of the investigated ncRNAs in primary CRC in comparison to metastases, suggesting their important role in the development of metastases. Finally, the observed positive regulation between the expression of all these RNAs suggests that $D C N$ and $m i R-200 \mathrm{c}$ might be regulated in an indirect rather than a direct manner. However, our study provides further evidence of an important role not only of $D C N$ and $m i R-200 c$ but also of lncRNAs MALAT1, lncTCF7 and ZFAS1 in the development of metastases in CRC.

Author Contributions: Conceptualisation, N.Z. and E.B.; methodology, M.Ž.; validation, K.U.; formal analysis, K.U. and E.B.; resources, N.Z. and J.G.; writing—original draft preparation, M.Ž.; writingreview and editing, E.B. and N.Z.; visualisation, M.Ž.; supervision, J.G., E.B. and N.Z.; project administration, E.B. and N.Z.; funding acquisition, E.B. and N.Z. All authors have read and agreed to the published version of the manuscript.

Funding: This study was funded by the Slovenian Research Agency (research core funding No P3-0054 and project funding J3-1754).

Institutional Review Board Statement: The study was conducted in accordance with the Declaration of Helsinki, and the protocol was approved by the Ethics Committee of the National Medical Ethics Committee of the Republic of Slovenia (approval No. 0120-88/2018/4).

Informed Consent Statement: Not applicable.

Data Availability Statement: The data presented in this study are available on request from the corresponding author.

Conflicts of Interest: The authors declare no conflict of interest.

\section{References}

1. Neill, T.; Schaefer, L.; Iozzo, R.V. Decorin: A guardian from the matrix. Am. J. Pathol. 2012, 181, 380-387. [CrossRef]

2. Jarvinen, T.A.; Prince, S. Decorin: A growth factor antagonist for tumor growth inhibition. Biomed. Res. Int. 2015, 2015, 654765. [CrossRef]

3. Augoff, K.; Rabczynski, J.; Tabola, R.; Czapla, L.; Ratajczak, K.; Grabowski, K. Immunohistochemical study of decorin expression in polyps and carcinomas of the colon. Med. Sci. Monit. 2008, 14, CR530-CR535.

4. Nyman, M.C.; Sainio, A.O.; Pennanen, M.M.; Lund, R.J.; Vuorikoski, S.; Sundstrom, J.T.; Jarvelainen, H.T. Decorin in human colon cancer: Localization in vivo and effect on cancer cell behavior in vitro. J. Histochem. Cytochem. 2015, 63, 710-720. [CrossRef]

5. Liu, Z.; Yang, Y.; Zhang, X.; Wang, H.; Xu, W.; Wang, H.; Xiao, F.; Bai, Z.; Yao, H.; Ma, X.; et al. An oncolytic adenovirus encoding decorin and granulocyte macrophage colony stimulating factor inhibits tumor growth in a colorectal tumor model by targeting pro-tumorigenic signals and via immune activation. Hum. Gene. Ther. 2017, 28, 667-680. [CrossRef]

6. Moreth, K.; Iozzo, R.V.; Schaefer, L. Small leucine-rich proteoglycans orchestrate receptor crosstalk during inflammation. Cell Cycle 2012, 11, 2084-2091. [CrossRef]

7. Theocharis, A.D.; Skandalis, S.S.; Gialeli, C.; Karamanos, N.K. Extracellular matrix structure. Adv. Drug Deliv. Rev. 2016, 97, 4-27. [CrossRef] [PubMed]

8. Sofeu Feugaing, D.D.; Gotte, M.; Viola, M. More than matrix: The multifaceted role of decorin in cancer. Eur. J. Cell Biol. 2013, 92, 1-11. [CrossRef] [PubMed]

9. Theocharis, A.D.; Karamanos, N.K. Proteoglycans remodeling in cancer: Underlying molecular mechanisms. Matrix Biol. 2019, 75-76, 220-259. [CrossRef] [PubMed]

10. Zlajpah, M.; Hauptman, N.; Bostjancic, E.; Zidar, N. Differential expression of extracellular matrixrelated genes DCN, EPHA4, FN1, SPARC, SPON2 and SPP1 in colorectal carcinogenesis. Oncol. Rep. 2019, 42, 1539-1548. [CrossRef]

11. Cox, T.R. The matrix in cancer. Nat. Rev. Cancer 2021, 21, 217-238. [CrossRef] 
12. Theocharis, A.D. Human colon adenocarcinoma is associated with specific post-translational modifications of versican and decorin. Biochim. Biophys. Acta 2002, 1588, 165-172. [CrossRef]

13. Ala, U. Competing endogenous RNAs and cancer: How coding and non-coding molecules cross-talk can impinge on disease. Int. J. Biochem. Cell. Biol. 2021, 130, 105874. [CrossRef]

14. Kusnadi, E.P.; Timpone, C.; Topisirovic, I.; Larsson, O.; Furic, L. Regulation of gene expression via translational buffering. Biochim. Biophys. Acta Mol. Cell Res. 2021, 1869, 119140. [CrossRef]

15. Tao, M.; Zheng, M.; Xu, Y.; Ma, S.; Zhang, W.; Ju, S. CircRNAs and their regulatory roles in cancers. Mol. Med. 2021, 27, 94 [CrossRef]

16. Kumar, S.; Mohapatra, T. Deciphering epitranscriptome: Modification of mRNA bases provides a new perspective for posttranscriptional regulation of gene expression. Front. Cell Dev. Biol. 2021, 9, 628415. [CrossRef] [PubMed]

17. Liu, F.; Song, Z.M.; Wang, X.D.; Du, S.Y.; Peng, N.; Zhou, J.R.; Zhang, M.G. Long non-coding RNA signature for liver metastasis of colorectal cancers. Front. Cell Dev. Biol. 2021, 9, 707115. [CrossRef] [PubMed]

18. Sole, C.; Lawrie, C.H. MicroRNAs in metastasis and the tumour microenvironment. Int. J. Mol. Sci. 2021, 22, 4859. [CrossRef] [PubMed]

19. Tang, R.Y.; Wang, Z.; Chen, H.Q.; Zhu, S.B. Negative correlation between miR-200c and decorin plays an important role in the pathogenesis of colorectal carcinoma. Biomed. Res. Int. 2017, 2017, 1038984. [CrossRef]

20. Pa, M.; Naizaer, G.; Seyiti, A.; Kuerbang, G. Long noncoding RNA MALAT1 functions as a sponge of miR-200c in ovarian cancer. Oncol. Res. 2017, 21, 333. [CrossRef] [PubMed]

21. Zhao, J.; Zhang, L.; Zheng, L.; Hong, Y.; Zhao, L. LncRNATCF7 promotes the growth and self-renewal of glioma cells via suppressing the miR-200c-EpCAM axis. Biomed. Pharmacother. 2018, 97, 203-208. [CrossRef]

22. O'Brien, S.J.; Fiechter, C.; Burton, J.; Hallion, J.; Paas, M.; Patel, A.; Patel, A.; Rochet, A.; Scheurlen, K.; Gardner, S.; et al. Long non-coding RNA ZFAS1 is a major regulator of epithelial-mesenchymal transition through miR-200/ZEB1/E-cadherin, vimentin signaling in colon adenocarcinoma. Cell Death Discov. 2021, 7, 61. [CrossRef]

23. Gao, Z.; Zhou, H.; Wang, Y.; Chen, J.; Ou, Y. Regulatory effects of lncRNA ATB targeting miR-200c on proliferation and apoptosis of colorectal cancer cells. J. Cell Biochem. 2020, 121, 332-343. [CrossRef]

24. Youn, Y.H.; Byun, H.J.; Yoon, J.H.; Park, C.H.; Lee, S.K. Long noncoding RNA N-BLR upregulates the migration and invasion of gastric adenocarcinoma. Gut Liver 2019, 13, 421-429. [CrossRef]

25. Wang, B.; Zheng, J.; Li, R.; Tian, Y.; Lin, J.; Liang, Y.; Sun, Q.; Xu, A.; Zheng, R.; Liu, M.; et al. Long noncoding RNA LINC02582 acts downstream of miR-200c to promote radioresistance through CHK1 in breast cancer cells. Cell Death Dis. 2019, 10, 764. [CrossRef] [PubMed]

26. Meng, L.; Ma, P.; Cai, R.; Guan, Q.; Wang, M.; Jin, B. Long noncoding RNA ZEB1-AS1 promotes the tumorigenesis of glioma cancer cells by modulating the miR-200c/141-ZEB1 axis. Am. J. Transl. Res. 2018, 10, 3395-3412. [PubMed]

27. Zhang, M.; Wang, F.; Xiang, Z.; Huang, T.; Zhou, W.B. LncRNA XIST promotes chemoresistance of breast cancer cells to doxorubicin by sponging miR-200c-3p to upregulate ANLN. Clin. Exp. Pharmacol. Physiol. 2020, 47, 1464-1472. [CrossRef] [PubMed]

28. Han, Z.; Shi, L. Long non-coding RNA LUCAT1 modulates methotrexate resistance in osteosarcoma via miR-200c/ABCB1 axis Biochem. Biophys. Res. Commun. 2018, 495, 947-953. [CrossRef]

29. Reszegi, A.; Horvath, Z.; Karaszi, K.; Regos, E.; Postnikova, V.; Tatrai, P.; Kiss, A.; Schaff, Z.; Kovalszky, I.; Baghy, K. The protective role of decorin in hepatic metastasis of colorectal carcinoma. Biomolecules 2020, 10, 1199. [CrossRef]

30. Han, B.; Feng, D.; Yu, X.; Zhang, Y.; Liu, Y.; Zhou, L. Identification and interaction analysis of molecular markers in colorectal cancer by integrated bioinformatics analysis. Med. Sci. Monit. 2018, 24, 6059-6069. [CrossRef]

31. Latham, G.J. Normalization of microRNA quantitative RT-PCR data in reduced scale experimental designs. Methods Mol. Biol. 2010, 667, 19-31. [CrossRef] [PubMed]

32. Chen, J.; Wang, W.; Zhang, Y.; Hu, T.; Chen, Y. The roles of miR-200c in colon cancer and associated molecular mechanisms Tumour Biol. 2014, 35, 6475-6483. [CrossRef] [PubMed]

33. Muto, Y.; Suzuki, K.; Kato, T.; Tsujinaka, S.; Ichida, K.; Takayama, Y.; Fukui, T.; Kakizawa, N.; Watanabe, F.; Saito, M.; et al. Heterogeneous expression of zinc-finger E-box-binding homeobox 1 plays a pivotal role in metastasis via regulation of miR-200c in epithelial-mesenchymal transition. Int. J. Oncol. 2016, 49, 1057-1067. [CrossRef]

34. Jepsen, R.K.; Novotny, G.W.; Klarskov, L.L.; Christensen, I.J.; Hogdall, E.; Riis, L.B. Investigating intra-tumor heterogeneity and expression gradients of miR-21, miR-92a and miR-200c and their potential of predicting lymph node metastases in early colorectal cancer. Exp. Mol. Pathol. 2016, 101, 187-196. [CrossRef]

35. Hur, K.; Toiyama, Y.; Takahashi, M.; Balaguer, F.; Nagasaka, T.; Koike, J.; Hemmi, H.; Koi, M.; Boland, C.R.; Goel, A. MicroRNA200c modulates epithelial-to-mesenchymal transition (EMT) in human colorectal cancer metastasis. Gut 2013, 62, 1315-1326. [CrossRef] [PubMed]

36. Li, W.; Chang, J.; Tong, D.; Peng, J.; Huang, D.; Guo, W.; Zhang, W.; Li, J. Differential microRNA expression profiling in primary tumors and matched liver metastasis of patients with colorectal cancer. Oncotarget 2017, 8, 35783-35791. [CrossRef] [PubMed]

37. Pavlic, A.; Urh, K.; Stajer, K.; Bostjancic, E.; Zidar, N. Epithelial-mesenchymal transition in colorectal carcinoma: Comparison between primary tumor, lymph node and liver metastases. Front. Oncol. 2021, 11, 662806. [CrossRef] 
38. Chen, Y.; Yu, X.; Xu, Y.; Shen, H. Identification of dysregulated lncRNAs profiling and metastasis-associated lncRNAs in colorectal cancer by genome-wide analysis. Cancer Med. 2017, 6, 2321-2330. [CrossRef]

39. Ma, M.; Li, L.; Long, F.; Xiao, H.; Lu, M.; Lin, C. MiR-133b inhibits colorectal cancer metastasis via lncRNA-LUCAT1. Future Oncol. 2021, 17, 1013-1023. [CrossRef]

40. Liu, S.J.; Dang, H.X.; Lim, D.A.; Feng, F.Y.; Maher, C.A. Long noncoding RNAs in cancer metastasis. Nat. Rev. Cancer 2021, 21, 446-460. [CrossRef]

41. Li, T.; Zhu, J.; Wang, X.; Chen, G.; Sun, L.; Zuo, S.; Zhang, J.; Chen, S.; Ma, J.; Yao, Z.; et al. Long non-coding RNA lncTCF7 activates the Wnt/beta-catenin pathway to promote metastasis and invasion in colorectal cancer. Oncol. Lett. 2017, 14, 7384-7390. [CrossRef] [PubMed]

42. Jin, F.S.; Wang, H.M.; Song, X.Y. Long non-coding RNA TCF7 predicts the progression and facilitates the growth and metastasis of colorectal cancer. Mol. Med. Rep. 2018, 17, 6902-6908. [CrossRef] [PubMed]

43. Chen, D.L.; Chen, L.Z.; Lu, Y.X.; Zhang, D.S.; Zeng, Z.L.; Pan, Z.Z.; Huang, P.; Wang, F.H.; Li, Y.H.; Ju, H.Q.; et al. Long noncoding RNA XIST expedites metastasis and modulates epithelial-mesenchymal transition in colorectal cancer. Cell Death Dis. 2017, 8, e3011. [CrossRef]

44. Liu, X.; Cui, L.; Hua, D. Long noncoding RNA XIST regulates miR-137-EZH2 axis to promote tumor metastasis in colorectal cancer. Oncol. Res. 2018, 27, 99-106. [CrossRef] [PubMed]

45. Wang, W.; Xing, C. Upregulation of long noncoding RNA ZFAS1 predicts poor prognosis and prompts invasion and metastasis in colorectal cancer. Pathol. Res. Pract. 2016, 212, 690-695. [CrossRef]

46. Shi, L.; Hong, X.; Ba, L.; He, X.; Xiong, Y.; Ding, Q.; Yang, S.; Peng, G. Long non-coding RNA ZNFX1-AS1 promotes the tumor progression and metastasis of colorectal cancer by acting as a competing endogenous RNA of miR-144 to regulate EZH2 expression. Cell Death Dis. 2019, 10, 150. [CrossRef]

47. Deng, H.; Wang, M.; Xu, Q.; Yao, H. ZFAS1 promotes colorectal cancer metastasis through modulating miR-34b/SOX4 targeting. Cell Biochem. Biophys. 2021, 79, 387-396. [CrossRef] 